\section{ARTICLE}

Annette Walling and Gareth Clancy

\section{Office for National Statistics}

\section{SUMMARY}

This article considers the extent of underemployment in the UK labour market. It begins by considering published unemployment and part-time work estimates, showing potential labour supply in the UK economy. Analysis is then presented which develops a measure of time-related underemployment using the Labour Force Survey (LFS) which looks at the additional hours that people in employment want to work. Further analysis describes recent trends in underemployment levels and rates, noting the changes that occurred as the UK economy contracted. The article also presents estimates of the volume of underemployment, in terms of the number of extra hours that underemployed people want to work, a useful indicator of potential capacity in the economy.

\title{
Underemployment in the UK labour market
}

1 etween Q2 2008 and Q3 2009 the economic output of the UK economy, as measured by gross domestic product (GDP) fell by 6.0 percentage points. Reductions in economic output tend to mean that demand for labour input falls as well. As in previous recessions, labour supply was greater than labour demand and this meant unemployment increased. This excess labour supply is one measure of underused capacity within the labour market, and is shown in Figure 1.

Unemployment levels and rates identify those people who are not in employment, who want and are seeking work. The potential labour supply covered by unemployed people is important because from the unemployed person's point of view no employment income is earned. From an employer and government perspective, it indicates the extent of slack in the labour market. However, the economy has extra capacity, as people already in employment may prefer to work additional hours. This is known as time-related underemployment and is a useful indicator of potential capacity in the economy.

Underemployment in economic literature is used to describe three alternative scenarios. It explains situations where the skills of a highly qualified person are underused. It also can be used as an alternative description for overstaffing, where employees are not fully used in terms of their productive capacity. In the context of this article the term is used to describe a third scenario: where a person wants to work more hours than is usual or stated under their current employment contract (see Bollinger et al 2003).

One way of looking at this disequilibrium is through involuntary part-time work. The US Bureau of Labor Statistics defines involuntary part-time workers as individuals who wanted full-time jobs, but worked less than 35 hours during the survey reference week because of economic reasons. The primary economic reasons include, a reduction in hours following unfavourable business conditions or the inability to find fulltime work. The Bureau of Labor Statistics published a short note in 2008 (see Issues in Labor Statistics 2008) showing how levels of this indicator began to increase before the official onset of the U.S recession (as defined by the National Bureau of Economic Research).

In the UK, the numbers of part-time workers who could not find a full-time job are published as part of the Labour Market monthly statistical bulletin. But these estimates do not necessarily include people who experienced a reduction in hours because of unfavourable economic circumstances (as in the US definition). These estimates are shown in Figure 2. The increase in the levels of part-time workers who could not find a full-time job in the UK followed a similar pattern to that found in the US, with the increase beginning in Q1 2005, over three years before the first economic contraction. However, even this separation of full and 


\section{Figure 1}

\section{Unemployment rate and GDP1}

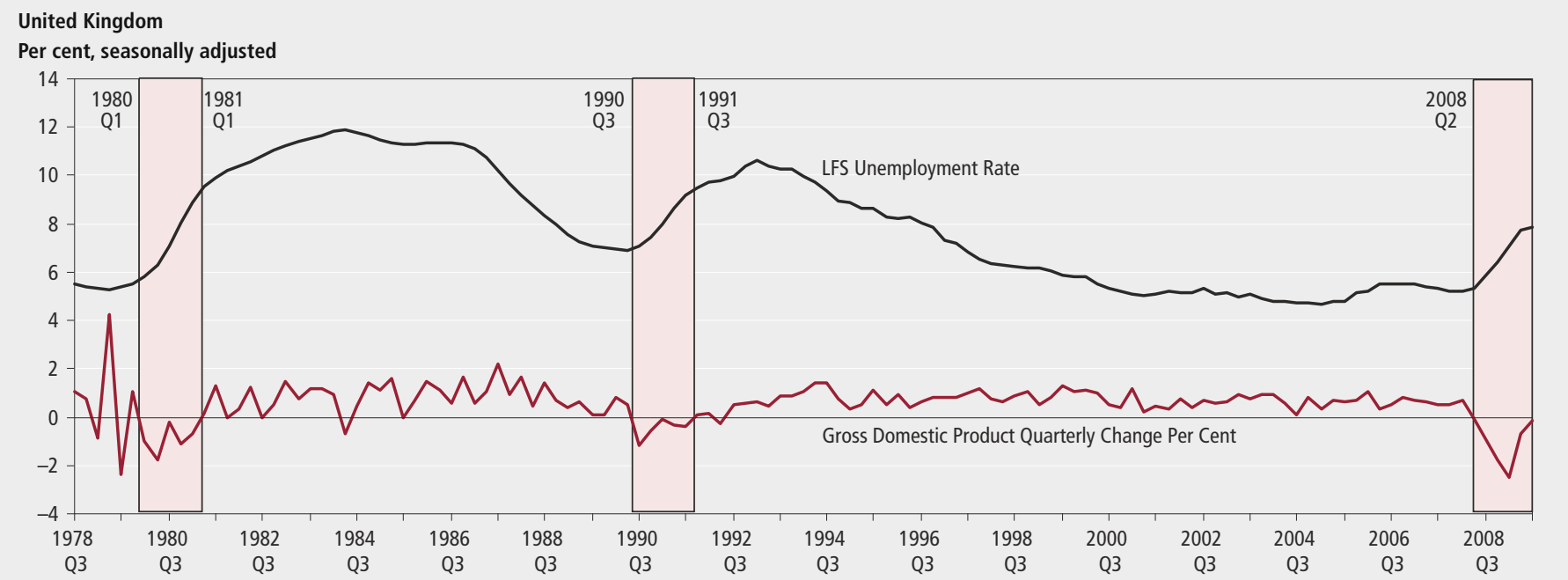

Note:

1 Shaded areas of the chart correspond to periods of negative GDP growth.

Source: Labour Force Survey and National Accounts

\section{Figure 2}

\section{Part-time workers who could not find a full-time job ${ }^{1,2}$}

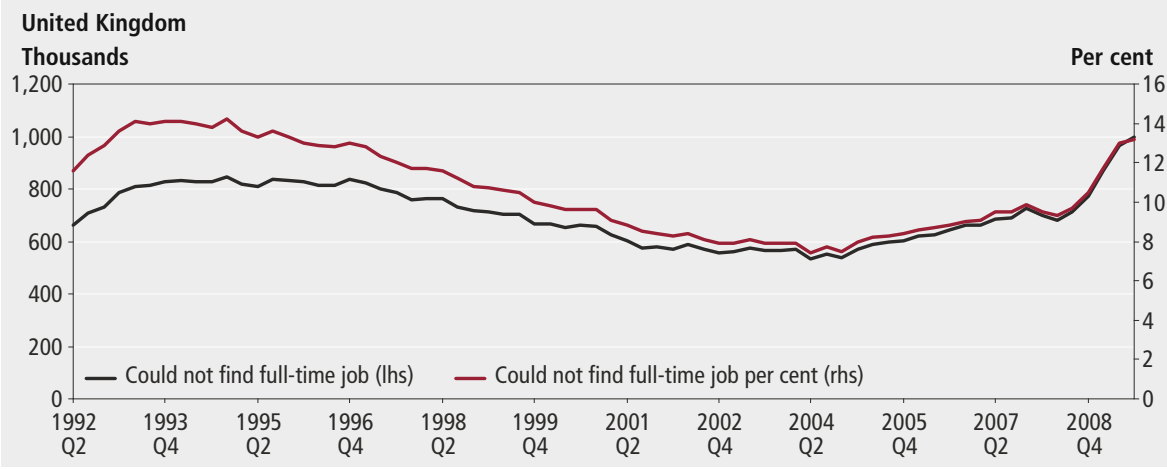

Note:

1 Seasonally adjusted data.

2 Could not find a full-time job as a percentage of all part-time workers

part-time work neglects potential capacity within the labour market.

Underemployment levels and rates are generally higher than the number and proportion of involuntary part-time workers. This is because a person may be willing and available to work longer hours whatever their reason for taking a part-time job, and even if their job is full-time. In addition, there is no internationally agreed definition of part-time work and the LFS full-time/part-time split is therefore based on respondent self-classification. The LFS full-time and part-time categories each cover a wide range of working patterns. For example, in Q3 2009, the usual weekly hours of work for people who classified their main job as part-time ranged from 1 to 40 hours. While the usual weekly hours of work for people who classified their main job as full-time ranged from 16 to 97 hours. Since it is possible for someone with a full-time job to be underemployed, if they are willing and available to work longer hours and provided that their hours of work do not exceed a defined threshold for underemployment (see Box $\mathbf{1}$ for International Labour Organisation (ILO) definition) more sophisticated estimates are needed than a simple full or part-time categorisation.

Furthermore, estimates of underemployment based on part-time workers who could not find a full-time job do not quantify the extent to which full or part-time workers are underemployed. In order to analyse the extent of time-related underemployment any analysis needs to consider the labour supply decision of all employees in terms of additional hours.

The labour supply decision under the neo-classical model of labour-leisure choice assumes that a person can choose the hours they work from a continuous distribution (see Borjas 1996), that is if they have a preference for working 31.5 hours, then they will be able to find work that meets that preference. In the real world hours are not this flexible. As explained in Simic (2002) the employer, institutions like trade unions, economic conditions and the degree of labour mobility, all determine the actual hours offered to workers. This means that the preferences of workers in terms of hours and the hours they are offered, will inevitably not equal each other in some cases.

\section{Measuring underemployment using the LFS}

To be classified as underemployed, a person must satisfy all three of the underemployment criteria set out in Box 1 (willing to work more hours, available to do so and worked less than the specified hours of work threshold). This section describes how underemployment can be measured using information from the UK Labour Force Survey (LFS).

Wanting and available to work longer hours

The LFS collects information on the numbers of employed people who:

- were looking for an additional job in the reference week, or

- were looking for a new job with longer hours to replace their current (main) job in the reference week, or

- wanted to work longer hours in their current job (at their basic rate of pay)

These three categories can be combined to give the total number of people wanting to work more hours. It should be noted however, that the first two categories 


\section{Box 1}

\section{International Labour Organisation (ILO) concepts and definitions}

Time-related underemployment, as defined by the ILO, exists when the hours of work of an employed person are insufficient in relation to an alternative employment situation in which the person is willing and able to engage.

Underemployed people are those who, during the reference period that is used to define employment:

- were willing to work additional hours: meaning that they wanted another job in addition to their current job(s); wanted another job with more hours instead of their current job(s); or wanted to increase the total number of hours worked in their current job(s)

- were available to work additional hours within a period corresponding to the usual term of notice, given opportunities for additional work; and

- worked less than a specified number of hours during the reference period

The underemployment rate is the number of underemployed people as a percentage of the total in employment. Underemployment can also be expressed as a percentage of the economically active population.

The volume of underemployment is the aggregate number of extra hours that underemployed people want to work.

The ILO recommends that, in addition to measuring underemployment as defined above, countries should measure the total number of workers who were willing and available to work additional hours, regardless of the number of hours they actually worked (that is, without applying an hours of work threshold). The definition of underemployment does not require people to have actively sought additional hours of work. However, the ILO recommends that countries should distinguish between underemployed people who actively sought to work additional hours and those who did not. This is in order to assess, for analytical purposes, how willingness to work additional hours is expressed in terms of actions (see ILO underemployment resolution adopted in 1998 and Hussmans 2007). include only people who were seeking extra hours in the reference week, which is a narrower concept than wanting to work extra hours. In that respect, the information collected in the UK LFS is slightly different to the ILO definition of underemployment.

The questions about seeking an additional job or a replacement job with longer hours (LFS variables ADDJOB, LOOKM and PREFHR) were introduced into the LFS in 1992. A question asking people whether they want to work longer hours in their current job (UNDEMP) was added in 1996, but the question was changed in 1999 to include only those who want to work longer hours at their basic rate of pay. This change, which excludes workers wanting additional hours of work at enhanced pay rates, causes a discontinuity in the series for people wanting to work longer hours in their current job.

The LFS measures availability to work longer hours by asking people who want to work longer hours whether they could start working longer hours within two weeks. The availability question (UNDST) was introduced in 1997 for people seeking an additional job or replacement job and the coverage was extended in 1999 to include people wanting to work longer hours in their current job. This, together with the discontinuity in the UNDEMP question, means that it is only possible to estimate the total number of people wanting and available to work longer hours on a consistent basis back to 1999 .

\section{People who wanted to work more hours in 2009}

According to LFS estimates for Q3 2009, around 325,000 employed people were looking for an additional job, 459,000 were looking for a replacement job with longer hours and 2.7 million wanted to work longer hours in their current job. This gives a total of 3.5 million workers (12.1 per cent of the total in employment) who wanted to work longer hours, but does not take account of their availability to work these hours. Of these, 3.0 million (10.8 per cent of the total in employment) were available to start working longer hours within two weeks.

Almost 370,000 people wanted to work longer hours, but were not available to do so within two weeks. Overall, the most frequently cited reason for not being available was 'looking after family/home' (33.0 per cent), but women gave this reason more often than men (43.3 per cent and 11.9 per cent respectively). The next most common specific reason was being unable to leave their current job within two weeks. A quarter of people who wanted to but were unavailable to start working longer hours, gave this as their reason (29.4 per cent of men and 22.5 per cent of women). This suggests that the two weeks notice period assumed in the LFS question might not be appropriate for all jobs. A further 9.7 per cent were unavailable because they had to complete their education, and 7.5 per cent were unavailable because of health problems.
The remaining 25.1 per cent were unavailable for other reasons.

The number and proportion of people wanting and available to work longer hours have been following an upward trend since 2005 . There was a relatively sharp increase over the year to Q3 2009. The level increased by 605,000 (24.4 per cent) and the proportion increased by 2.3 percentage points. This was mainly driven by an increase in the number of workers who wanted to work longer hours in their current job. The numbers seeking an additional job or a replacement job with longer hours also increased by over 20 per cent, but the lower numbers in these groups meant their contribution to the total change was minimised (see Figure 3)

Applying an hours of work threshold The ILO recommends that an hours of work threshold should be applied, above which people who want and are available to work longer hours should not be classified as underemployed. It also recommends that the threshold should be based on total actual weekly hours worked and that the cut-off point should be chosen according to national circumstances.

An actual hours threshold is specified because underemployment statistics, like employment and unemployment statistics, should give a snapshot of the situation for a given point in time. Actual hours are specified in order to capture people who worked less than their usual hours due to economic circumstances (such as variable 


\section{Figure 3}

\section{Number of employed people wanting and available to work longer hours: by whether in current or a different job, 2000 to $2009^{1}$}

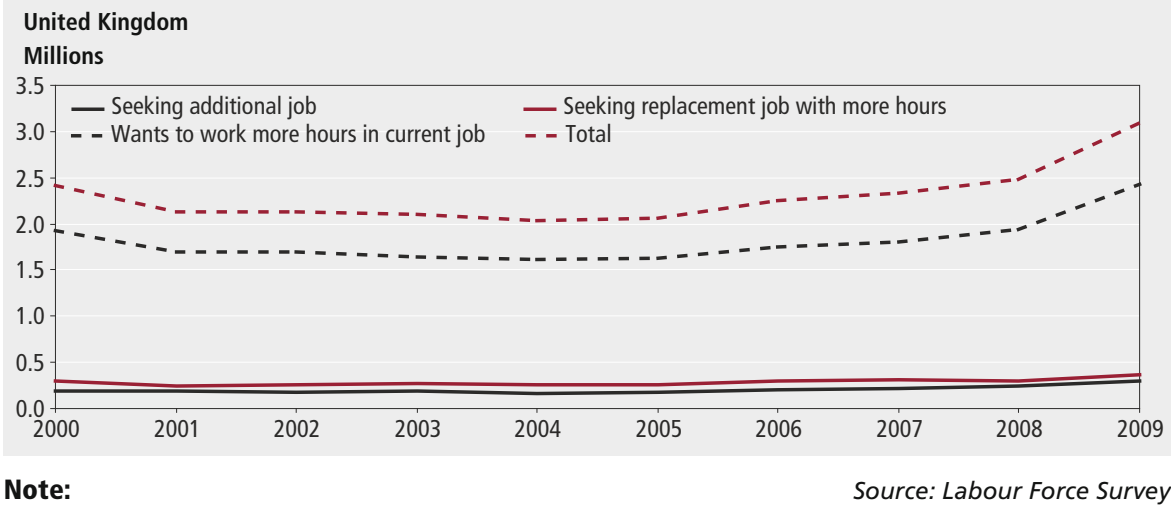

1 July to September each year, not seasonally adjusted.

work hours, labour disputes, short-time working or interrupted seasonal work).

A disadvantage of applying a threshold based on actual hours worked is that most people who work less than their usual weekly hours in the reference week do so for non-economic reasons (such as holidays or sick leave). In Q3 2009, 35.1 per cent of the workforce worked less than their usual weekly hours and 60.1 per cent of these (21.1 per cent of the total workforce) did so for non-economic reasons. An alternative approach is to apply a threshold based on a constructed hours measure, where constructed hours are defined as being equal to actual weekly hours worked, unless the person worked less hours than usual for non-economic reasons, in which case their constructed hours equals their usual weekly hours. This approach prevents people from being classified as underemployed if they usually work more than the threshold number of hours, but did not do so during the reference week for non-economic reasons.

Whichever hours of work variable the threshold is based on, it is necessary to establish an appropriate cut-off point.

Figure 4 illustrates the impact on estimates of the underemployment level for Q3 2009 when various hours of work thresholds are applied. When a threshold of 40 hours per week is applied the underemployment level is similar, regardless of the hours of work variable used. When thresholds below 40 hours are applied, the underemployment level becomes much lower. In addition, results for the three hours of work variables diverge, with actual hours producing the highest underemployment level. When thresholds higher than 40 hours are applied, the underemployment level increases gradually and the results for the three hours of work variables are similar.
In the preparation of this article thresholds based on actual, usual and constructed hours were all explored. Cut-offs were also considered, based on mean and median values, as well as working-time legislation. The analysis showed that whichever hours of work variable the threshold is based on, and whichever type of cut-off point is used, each method produces a similar trend in underemployment levels and rates. The method used in this article is to apply a threshold based on a constructed hours measure, with a cut-off based on the EU Working Time Regulations. These Regulations, which were implemented in the UK in 1998, stipulate that workers aged under 18 cannot work more than 40 hours a week and that those aged 18 and over cannot be forced to work more than 48 hours per week on average, although some occupations can opt out (see Working Time Regulations reference)

Applying a constructed hours of work threshold of 40 hours (for people aged under 18) or 48 hours (for people aged 18 and over) produces an underemployment level for Q3 2009 that is 243,000 (7.9 per cent) lower than it would be if the threshold had not been applied, and an underemployment rate that is 0.8 percentage points lower than it would be if the threshold had not been applied.

\section{LFS underemployment}

In the remainder of this article, underemployed people are defined as employed people:

- who were looking for an additional job or a replacement job with longer

\section{Figure 4}

Impact on estimates of underemployment levels when various hours of work thresholds are applied, 2009

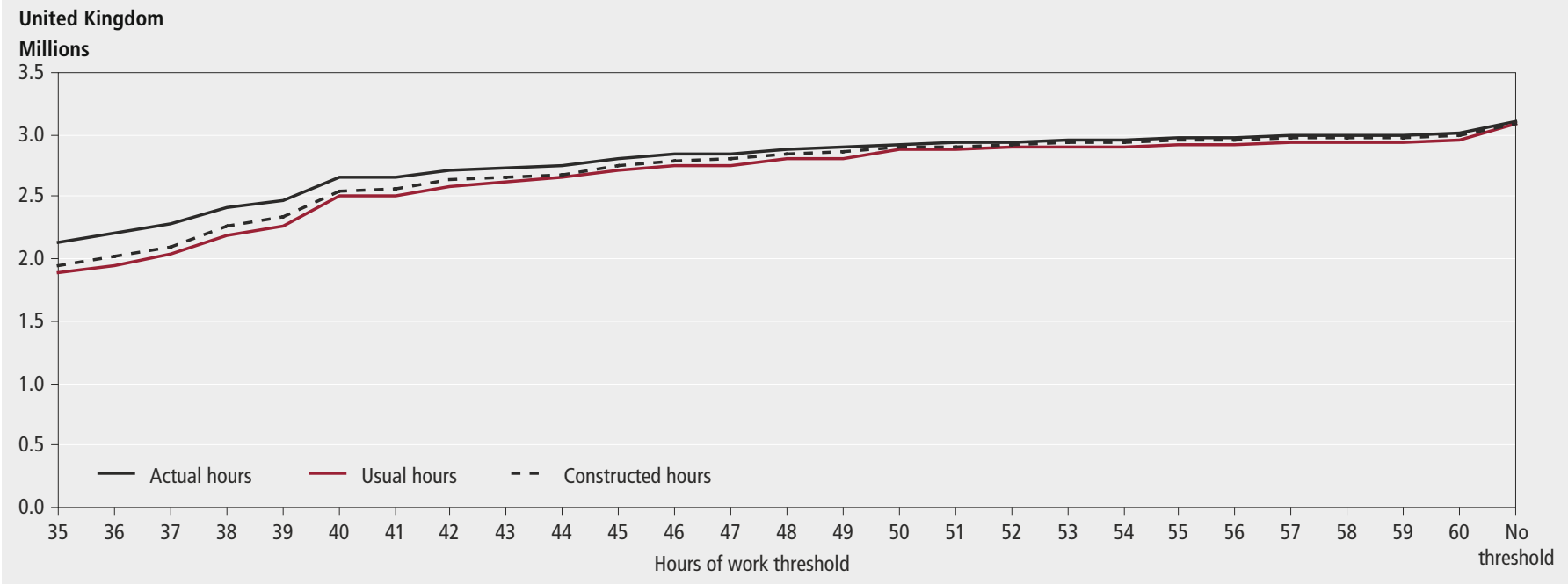


hours, or who wanted to work longer hours in their current job, and

- were available to start working longer hours within two weeks, and

- whose constructed weekly hours were 40 or less (for people aged under 18) or 48 or less (for people aged 18 and over)

These criteria are similar to those used by Simic (2002). The only difference being the thresholds applied in this article are 40 and 48 hours according to age, rather than the average sex-specific constructed hours.

Constructed hours are defined as being equal to actual weekly hours worked, except for people who worked less than their usual weekly hours in the reference week for non-economic reasons, in which case, their constructed weekly hours equals their usual weekly hours of work. Non-economic reasons include: holidays, sick leave, maternity/paternity and parental leave, other leave, training courses, changed jobs, and other personal reasons. Economic reasons include: hours of work/overtime varies; laid off/shorttime working for economic reasons, due to industrial disputes, or work interrupted by bad weather; or job ended and did not start a new one.

\section{Recent trends in underemployment}

Unemployment statistics are an important indicator of excess labour supply in the economy. They measure the number or proportion of economically active people who were without a job in the reference week, and were seeking and available for work. Underemployment statistics can be regarded as an additional indicator of potential labour supply, the difference being they measure unused labour resource among people already in employment. So while unemployment statistics measure situations of total lack of work, underemployment statistics measure situations of partial lack of work.

This section compares recent trends in underemployment with trends in unemployment. It also compares underemployment figures with statistics on part-time workers who could not find a full-time job (first looked at in Figure 2).

\section{Underemployment and} unemployment

Figure 5 shows estimates of underemployment and unemployment levels over the same period. The trend in underemployment is similar, though not identical, to the trend in unemployment over this period. In general, a decrease in underemployment corresponded with a decrease in unemployment, and an increase in underemployment corresponded with an increase in unemployment. Given that unemployment measures situations of complete lack of work and underemployment measures situations of insufficient hours of work, it follows that employers will vary full and partial employment offers in a similar way according to prevailing economic circumstances.

According to LFS estimates for Q3 2009 , there were 2.6 million unemployed people in the UK and 2.8 million underemployed people. While 9.0 per cent of the economically active population were underemployed, in comparison with 8.1 per cent who were unemployed. The underemployment rate (underemployed as a proportion of the total in employment) was 9.9 per cent.

Between 2000 and the end of 2007 the UK economy recorded positive growth, as measured by gross domestic product (GDP), in every quarter. Figure 5 and Figure 6 show that the underemployment level and rate fell between Q3 2000 and Q3 2001, after which these measurements of underemployment were relatively stable for the four years to Q3 2005. Underemployment levels were close to 1.9 million over this period, while the underemployment rate remained below 7.0 per cent.

In Q2 2008, the UK economy contracted, and labour market statistics since this point have indicated a weaker demand for labour. There was a relatively sharp rise in both unemployment and underemployment during the 2008 to 2009 recession. The unemployment level increased by 632,000 (32.9 per cent) over the year to Q3 2009 to reach 2.6 million (not seasonally adjusted). The underemployment level increased by 594,000 ( 26.4 per cent) over the year to Q3 2009 to stand at 2.8 million. The unemployment rate increased by 2.0 percentage points, but the

\section{Figure 5}

Underemployment levels and unemployment levels, 2000 to $2009^{1}$

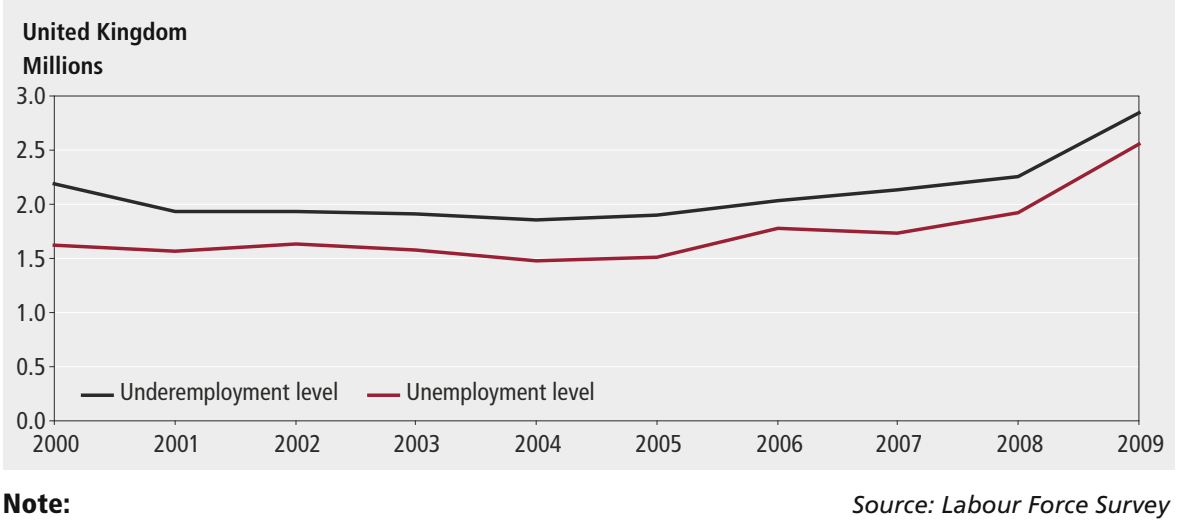

1 July to September of each year, not seasonally adjusted.

\section{Figure 6}

Underemployment rates ${ }^{1}$ and unemployment rates, $^{2} 2000$ to $2009^{3}$

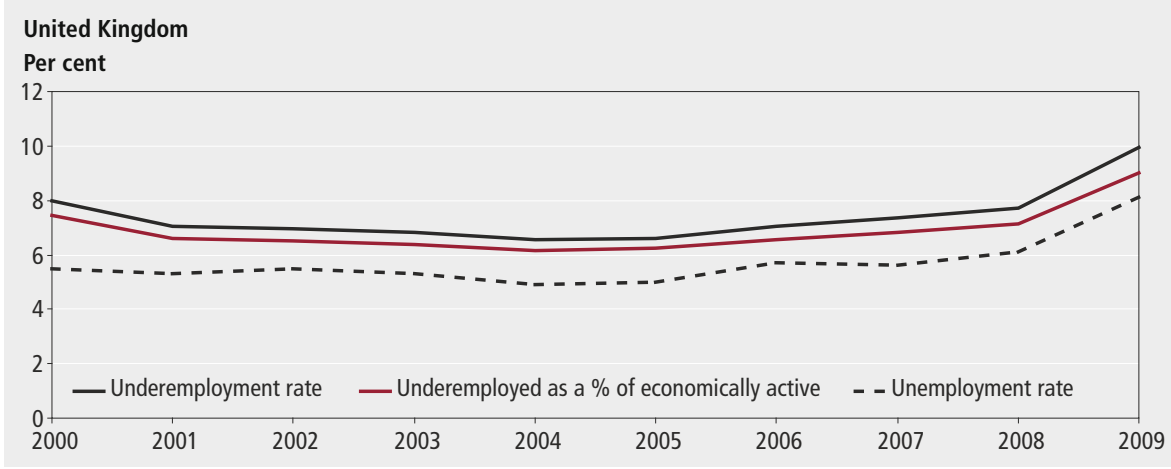

Notes:

Source: Labour Force Survey

1 The underemployment rate is the number of underemployed people as a percentage of the total in employment. Base for percentages excludes people who did not answer the underemployment questions.

2 The unemployment rate is the number of unemployed people as a percentage of the economically active population.

3 July to September of each year, not seasonally adjusted. 
underemployment rate increased by 2.2 percentage points over the same period.

The sharp rise in underemployment over the year to Q3 2009 was mainly driven by an increase in the subgroup of underemployed workers who wanted to work longer hours in their current job. Of the 2.8 million people who were underemployed in Q3 2009, 2.2 million wanted to work longer hours in their current job. This figure is 474,000 higher than the previous year. A further 349,000 were seeking a replacement job with longer hours (up 57,000 on the year) and 279,000 were seeking an additional job (up 63,000 on the year).

Employees composed a large component (2.5 million) of the underemployed total in Q3 2009, as opposed to self-employed. The LFS asks employees who want to work longer hours whether they have approached their employer about working more hours, and if so whether their employer is able to increase their hours. In Q3 2009, 49.6 per cent of underemployed employees had approached their employer about working more hours, of which 16.3 per cent said that their employer was able to increase their hours. This figure is 3.1 percentage points lower than the previous year. It is difficult to assess whether this reflects a reduced demand for labour during the recession, because the LFS does not ask people how long it is since they approached their employer about working longer hours, nor does the survey ask people why their employer was unable to increase their hours.

\section{Part-time workers who could} not find a full-time job and underemployment

The proportion of the people in employment who worked part-time remained fairly stable over the ten years to Q2 2009, at around 26 per cent.

The proportion of men in part-time employment increased by 2.9 percentage points over the same period, to 11.9 per cent. At the same time the proportion of women in part-time employment decreased by 1.7 percentage points to 42.7 per cent.

Most part-time workers had taken a part-time job for personal reasons (because they did not want a full-time job, or they were students, or they had health problems); while others had done so because they could not find a full-time job. The latter group are sometimes called involuntary part-time workers. However, it should be noted that the UK and US definitions of involuntary workers differ because the US definition also includes people with a full-time job who worked part-time in the reference week for economic reasons, as well as people who took a part-time job because they could not find a full-time job.

The underemployment level for Q3 2009 includes 1.6 million people who classified their main job as part-time and 1.3 million people who classified their job as full-time. The number of involuntary part-time workers for the same period was 1.0 million. About a fifth of part-time workers were underemployed (21.1 per cent), whereas only 13.4 per cent had taken a part-time job because they could not find a full-time job.

Of the 1.6 million part-time workers who were underemployed, only 38.2 per cent had taken a part-time job because they could not find a full-time job. Although most involuntary part-time workers were classified as underemployed, over a third of them were not (39.1 per cent). This was because either they did not want to work longer hours, or because they were not available to do so within two weeks. A breakdown by length of service with current employer indicates that most of the involuntary part-time workers who were not underemployed had been in their current job for over a year (73.6 per cent). It is possible that they took a part-time job because they were unable to find a full-time job at the time, but their circumstances may have changed in the meantime, and this could explain why they were unwilling and/ or unavailable to work longer hours at the time of their LFS interview.

Figure 7 shows underemployment rates for full-time and part-time workers, and the proportion of part-time workers who took a part-time job because they could not find a full-time job, for each of the past ten years. The magnitude of changes in the underemployment rate for part-time workers over twelve months tend to be larger than for full-time workers between 2001 and 2009. This fits with the relative size of the levels of the two groups. Figure 7 also shows that during the period 2001 to 2007, full-time underemployment remained relatively stable at just below 4.0 per cent. Part-time underemployment remained over 16.0 per cent over the ten-year period, except for lows of 15.5 per cent and 15.8 per cent in 2004 and 2005. The low in 2004 occurred at the same time as the low of 7.9 per cent in the proportion of part-time workers unable to find a full-time job.

There was a relatively sharp rise in underemployment over the year to Q3 2009, particularly among people who classified their job as part-time. The underemployment rate for part-time workers increased by 3.3 percentage points, to 21.1 per cent, while underemployment rate for full-time workers increased by 1.7 percentage points, to 6.0 per cent. The proportion of part-time workers who took a part-time job because they could not find a full-time job increased by 3.6 percentage points over the same period, to 13.4 per cent.

\section{Extra hours wanted}

The LFS asks people who want and are available to work longer hours, how many extra hours they would like to work each week, in addition to their

\section{Figure 7}

\section{Underemployment rates ${ }^{1}$ for full-time and part-time ${ }^{2}$ workers, and proportion of part-time workers who could not find a full-time job, 2000 to $2009^{3}$}

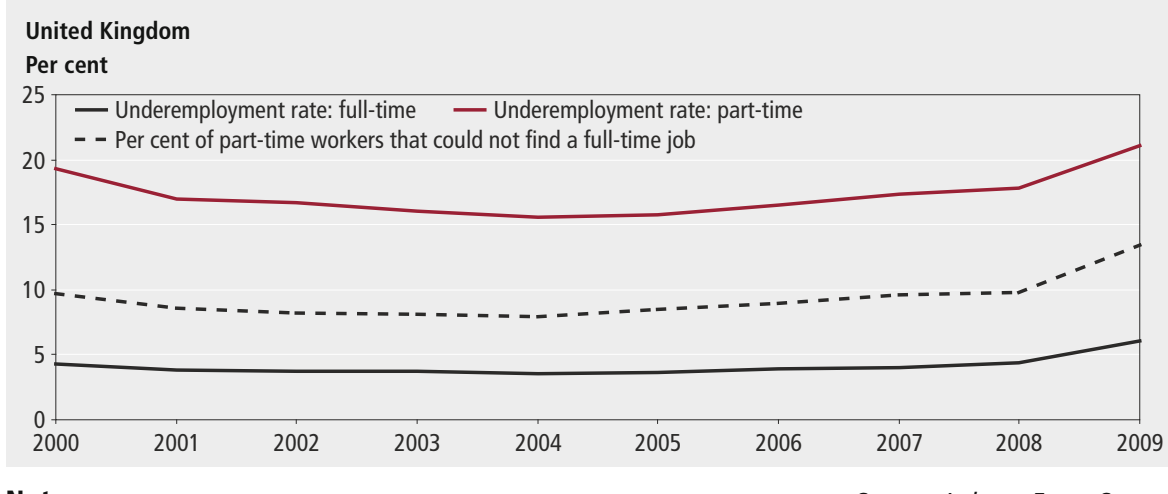

Notes:

Source: Labour Force Survey

1 Underemployed people as a percentage of the total in employment. Base for percentages excludes people who did not answer the underemployment questions.

2 The LFS full-time/part-time split is based on respondent self-classification.

3 July to September of each year, not seasonally adjusted. 
usual weekly hours of work. The results from this question (UNDHRS) can be used to calculate the average extra hours wanted by underemployed people, and to calculate their preferred weekly hours of work. Estimates for Q3 2009 indicate that underemployed people who classified their job as full-time wanted to work an extra 9 hours per week, on average. While underemployed people who classified their job as part-time wanted to work an extra 14 hours per week, on average. For underemployed people as a whole, the average number of extra hours wanted was 12 hours per week.

The preferred weekly hours of work for each underemployed person can be calculated as the sum of the extra hours they wanted and their usual weekly hours of work. However, around 20 per cent of underemployed people worked less than their usual weekly hours during the reference week for economic reasons, and it is possible that the figure they gave in answer to the UNDHRS question reflects a shortfall in their actual weekly hours, rather than a shortfall in their usual weekly hours. If so, then adding their extra hours wanted to their usual weekly hours will overstate their preferred hours of work. An alternative method is to calculate preferred weekly hours as the sum of extra hours wanted and constructed hours. This approach means that preferred hours are calculated as the sum of extra hours wanted and usual hours unless the person worked less hours than usual in the reference week for economic reasons, in which case, preferred hours equals extra hours wanted plus actual weekly hours. The figures given below have been produced on this basis.

According to LFS estimates for Q3 2009, underemployed people with a full-time job wanted to work 45 hours per week, on average. This is slightly higher than the average constructed weekly hours for fully-employed full-time workers (43 hours per week). Underemployed people with a part-time job wanted to work 31 hours per week, on average, which is 12 hours more than the average constructed hours for fully-employed part-time workers. The average preferred hours for underemployed people as a whole was 38 hours per week and this is the same as the average constructed weekly hours for people employed full-time.

\section{Volume of underemployment}

The volume of employment can be expressed either in terms of the number of people in employment, or in terms of the aggregate number of hours worked. Similarly, the amount of unused labour resource available in the economy can be expressed in terms of the number of people willing and available to work longer hours, or in terms of the aggregate number of hours they are willing and available to work. As mentioned in the previous section, the LFS asks people who want to work longer hours, how many extra hours they would like to work each week. The results from this question can be used to calculate the aggregate number of additional hours that underemployed people would like to work. This information, described by the ILO as the volume of underemployment, provides a measure of underused labour resource among those already in employment and complements information about underemployment levels and rates.

A total of 3.5 million workers wanted to work longer hours in Q3 2009, of which 3.0 million were available to start working longer hours within two weeks and 2.8 million of those were classified as underemployed. Figure 8 shows the total number of extra hours wanted for each of these groups and illustrates how the volume of underemployment is reduced when the availability criterion and the hours of work threshold are applied.

According to LFS estimates for Q3 2009, a total of 38.7 million extra hours were wanted by people who wanted to work longer hours. When people who were unavailable to start working extra hours within two weeks are excluded, along with people whose hours of work exceeded the threshold for underemployment, the volume of underemployment for Q3 2009 is 31.6 million hours.

The trend in the volume of underemployment over the past ten years is similar to the trend in underemployment levels and rates. There was a relatively sharp rise over the year to Q3 2009: the volume of underemployment increased by 6.2 million hours ( 24.6 per cent). This is mainly due to an increase of 594,000 in the number of people who were underemployed. The average number of extra hours wanted by underemployed workers remained at 12 hours per week between Q3 2008 and Q3 2009.

These changes fit in with the path of the economy from 2008 onwards. As labour demand, in terms of employment and hours weakened, people (the supply of labour) were not able to find the amount of work wanted. One reason for this is because people have financial commitments to meet, which require a certain level of income. Also, people may not revise their preferred work hours downwards because of lower wages unless they are aware of average wages weakening across the economy. It is also the case that some wages take time to adjust downwards, so people continue to seek a volume of work that matches previous wage offers.

The volume of underemployment can be broken down in terms of the three types of underemployed worker: people who were seeking an additional job (4 million hours); people who were seeking a replacement job with longer hours (6.1 million hours) and people who wanted to work longer hours in their current job (21.5 million hours).

\section{Figure 8}

\section{Volume of extra hours wanted, ${ }^{1}$ by availability ${ }^{2}$ and whether} underemployed, ${ }^{3} 2000$ to $2009^{4}$

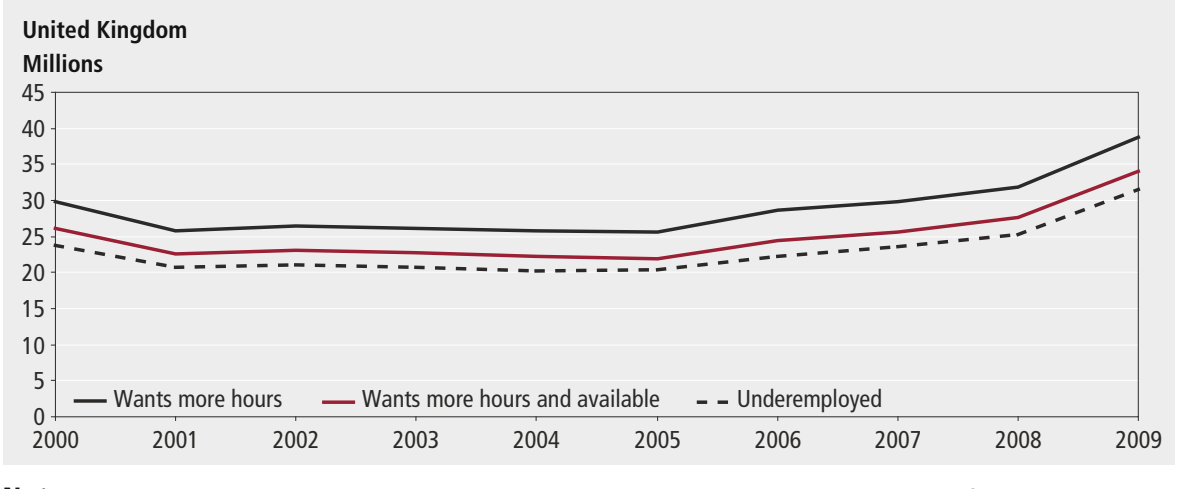

\section{Notes:}

Source: Labour Force Survey

1 Total extra hours wanted by all workers who wanted to work extra hours.

2 Total extra hours wanted by workers who wanted and were available to start working extra hours within two weeks.

3 Total extra hours wanted by underemployed workers.

4 July to September of each year, not seasonally adjusted. 
Table 1

Volume and rate of unutilised labour resource due to underemployment, 2000 to $2009^{6}$

\begin{tabular}{|c|c|c|c|c|c|c|}
\hline & $\begin{array}{r}\text { Underemployment level } \\
\text { (millions) }\end{array}$ & $\begin{array}{r}\text { Underemployment rate } \\
\text { (per cent) }{ }^{1}\end{array}$ & $\begin{array}{r}\text { Actual hours worked } \\
(\text { millions })^{2}\end{array}$ & $\begin{array}{r}\text { Volume of } \\
\text { underemployment } \\
\text { (millions of hours) }^{3}\end{array}$ & $\begin{array}{r}\text { Total potential } \\
\text { volume of hours } \\
\text { (millions of hours) }^{4}\end{array}$ & $\begin{array}{r}\text { Rate of unutilised hours } \\
\text { due to underemployment } \\
\text { (per cent) }\end{array}$ \\
\hline 2000 & 2.2 & 8.0 & 883.7 & 23.8 & 907.5 & 2.6 \\
\hline 2001 & 1.9 & 7.0 & 892.0 & 20.7 & 912.7 & 2.3 \\
\hline 2002 & 1.9 & 7.0 & 890.0 & 21.0 & 911.0 & 2.3 \\
\hline 2003 & 1.9 & 6.8 & 893.9 & 20.8 & 914.7 & 2.3 \\
\hline 2004 & 1.9 & 6.6 & 896.0 & 20.3 & 916.3 & 2.2 \\
\hline 2005 & 1.9 & 6.6 & 912.5 & 20.4 & 932.9 & 2.2 \\
\hline 2006 & 2.0 & 7.0 & 914.3 & 22.2 & 936.5 & 2.4 \\
\hline 2007 & 2.1 & 7.3 & 924.9 & 23.6 & 948.5 & 2.5 \\
\hline 2008 & 2.3 & 7.7 & 927.2 & 25.3 & 952.5 & 2.7 \\
\hline 2009 & 2.8 & 9.9 & 897.0 & 31.6 & 928.6 & 3.4 \\
\hline
\end{tabular}

\section{Notes:}

Source: Labour Force Survey

1 Underemployed people as a percentage of the total in employment. Base for percentages excludes people who did not answer he unemployment questions.

2 Total actual weekly hours worked in main and second jobs, including paid and unpaid overtime.

3 Total extra hours wanted by people who were underemployed.

4 The sum of total hours worked and the volume of underemployment.

5 Volume of underemployment as a percentage of the total potential volume of hours.

6 July to September of each year, not seasonally adjusted.

\section{Potential volume of hours worked}

The ILO defines the potential volume of hours worked, for people already in employment, as the sum of hours actually worked and the volume of underemployment. The rate of the volume of underemployment is calculated as the ratio between the volume of underemployment and the potential volume of hours worked, for people in employment. This gives a measure of the extent to which labour resources are underutilised as a result of underemployment.

For Q3 2009, the total number of hours actually worked was 897.0 million (not seasonally adjusted). This was lower than the actual hours worked in Q3 between 2005 and 2009. Over the same four year period the volume of underemployment increased from 20.4 million hours to reach 31.6 million hours in Q3 2009. The total potential volume of hours for people in employment was 928.6 million hours and the rate of unutilised hours due to underemployment was 3.4 per cent in Q2 2009. In other words, 3.4 per cent of the potential hours of work for people already in employment were unutilised due to underemployment (see Table 1).

However, it is worth bearing in mind that 19.1 per cent of underemployed workers worked less than their usual hours of work in the reference week for noneconomic reasons (such as holiday or sick leave). Therefore, they may not have been available to work all of the extra hours that they wanted to in that particular week. This means that the volume of underemployment, as defined by the
ILO, may tend to over-state the amount of unutilised labour resource that was actually available in the reference week. Having said this, some non-economic reasons are likely to be relatively consistent over time.

\section{Conclusions}

Underemployment statistics complement employment and unemployment statistics by measuring situations of partial lack of work. They provide an additional insight into the extent to which labour resources are available and used within the economy. Underemployment figures are more comprehensive than statistics on part-time workers who could not find a full-time job, because a person can be willing and available to work longer hours whatever their reasons for taking a part-time job, and even if they classify their job as fulltime. Also, people who took a part-time job because they could not find a full-time job at the time are not necessarily willing and available to work longer hours at present.

This article has demonstrated how the LFS can be used to produce estimates of underemployment using ILO recommendations. It suggests that using constructed hours as the standard methodology for calculating underemployment is preferable to solely using actual or usual hours worked. This is because actual hours worked can vary because of non-economic reasons, and constructed hours takes account of this fact.

According to estimates from the LFS, there were 2.8 million underemployed people in the UK in Q3 2009 (9.9 per cent of the total workforce, or 9.0 per cent of the economically active population). There has been a relatively sharp rise in underemployment during the current recession, alongside an increase in unemployment. The underemployment level for Q3 2009 was 594,000 (26.4 per cent) higher than the previous year and the underemployment rate was 2.2 percentage points higher than the previous year. The volume of underemployment, in terms of extra hours wanted, was 31.6 million hours for Q3 2009. This figure is 6.2 million hours (24.6 per cent) higher than the previous year. Approximately 3.4 per cent of the potential hours of work for people already in employment were unutilised due to underemployment.

These LFS estimates measuring underemployment can be explained in the context of a weakened economic outlook. As labour demand weakens, unless people revise downwards the amount of work they want, underemployment and unemployment will both increase. In the pre-recession period presented, all of the measures of underemployment and unemployment were relatively stable. This suggested some spare capacity in the economy in terms of labour input, but this is to be expected because employers cannot be perfectly flexible in terms of the number of hours they offer. When quarterly estimates of GDP contracted in 2008 this meant that new job offers (both full and part-time) were scarce, and existing jobs were cut back. This will have forced some people to take work that did not meet their needs in terms of hours worked and earnings, and hence increased underemployment levels and rates as shown. 


\section{ACKNOWLEDGEMENTS}

The authors would like to thank members of the Labour Market Analysis team, ONS for their help in producing this article.

\section{CONTACT}

四elmr@ons.gov.uk

\section{REFERENCES}

Anker R et al, 'Measuring decent work with statistical indicators', ILO, 2002 at: www.ilo.org/integration/resources/papers/ lang--en/docName--WCMS_079089/index.htm

Bollinger C, Coomes P, Berger M, 'Measuring Underemployment at the County Level' Discussion Paper Series University of Kentucky Centre for Poverty Research (2003) at: www.ukcpr.org/Publications/Bollinger_ DP2003-08.pdf

Borjas G (1996) 'Labor Economics' McGraw-Hill
Hussmans, R, 'Measurement of employment, unemployment and underemployment current international standards and issues in their application (ILO Bureau of StatisticS, 2007) at:

www.ilo.org/wcmsp5/groups/public/--dgreports/---integration/---stat/documents/ publication/wcms_088394.pdf

International Labour Organisation (ILO): 'Key Indicators of the Labour Market (KILM) 12: Time-related underemployment' at: www.ilo.org/public/english/employment/ strat/kilm/download/kilm12.pdf

International Labour Organisation (ILO), 'Resolution concerning the measurement of underemployment and inadequate employment situations, adopted by the $16^{\text {th }}$ ICLS (October 1998) at: www.ilo.org/wcmsp5/groups/public/--dgreports/---integration/---stat/ documents/normativeinstrument/ wcms_087487.pdf
Issues in Labor Statistics (2008), 'Involuntary Part-time work on the rise', United States Bureau of Labor Statistics, Summary 08-08 at:

www.bls.gov/opub/ils/pdf/opbils71.pdf

Simic M (2002), 'Underemployment and overemployment in the UK', Labour Market Trends Vol 110 (8) pp 399-414

For further information about the Working Time Regulations, see: www.berr.gov.uk/whatwedo/employment/ working-time-regs/index.html

\section{TECHNICAL NOTE}

The estimates included in this article are for the July to September quarter each year, ending in 2009. The employment, unemployment and hours of work figures presented are not seasonally adjusted (unless stated otherwise). Therefore, they do not match equivalent figures published in the monthly Labour Market statistical bulletin', which are seasonally adjusted. This is to ensure consistency with the estimates of underemployment, which have been produced from the LFS microdata.

The International Labour Organisation (ILO) definition of economic activity divides the labour force into two main groups: employed and unemployed. People are classified as being in employment if they worked for an hour or more during the reference week, or had a job that they were temporarily away from. People are classified as unemployed if they were without a job and were seeking and available for work. Employment and unemployment, as defined by the ILO, do not capture the diversity of circumstances that exist within the labour force. The ILO framework for measuring economic activity therefore incorporates the additional concept of time-related underemployment. Broadly speaking, underemployed people are people, already in employment, who want and are available to work longer hours than they currently do.

Statistics on time-related underemployment complement employment and unemployment statistics by measuring situations of partial lack of work. They provide an additional insight into the extent to which labour resources are available and used within the economy. Underemployment is also of interest from a social well-being perspective and is one of the core indicators within the ILO decent work framework (see ILO documents on 'Key Indicators of the Labour Market' and 'Measuring decent work').

Note

1 For the latest Labour Market Statistical Bulletin, see:

www.statistics.gov.uk/statbase/Product.asp?vlnk=1944 